\title{
Formas góticas, mudéjares y renacentistas en Ciudad Real ${ }^{*}$
}

\author{
María Cristina LóPEz LóPEZ \\ Universidad de Castilla-La Mancha \\ Departamento de Historia del Arte \\ mcristina_lopez@hotmail.com
}

\section{RESUMEN}

La actual demarcación territorial de Ciudad Real tuvo durante la Edad Media una posición estratégica para tropas cristianas y musulmanas, logrando con sus incursiones una tierra falta de un poblamiento estable, y, en consecuencia, una falta de unidad de estilo reflejada en arquitectura, escultura y pintura. No será hasta después de la Reconquista cuando convergen e interactúan formas cristianas y mudéjares con las posteriores llegadas de Italia.

Palabras clave: gótico; mudéjar; renacentista; Ciudad Real.

\section{Gothic, Mudejar and Renaissance Forms in Ciudad Real}

\begin{abstract}
In the Middle Ages, the territorial demarcation of Ciudad Real held a strategic position for Christian and Muslim troops, whose incursions resulted in a land which lacked a stable settlement and, as a consequence, a unity of style reflected in architecture, sculpture and paintings. It would not be until after the Reconquest that the Christian and Muslim forms converged and interacted with subsequent arrivals from Italy.
\end{abstract}

Key words: Gothic; Mudejar; Renaissance; Ciudad Real.

* El presente texto forma parte de la Tesis Doctoral que lleva por título La transición del arte gótico al renacimiento en la provincia de Ciudad Real, realizada en el marco del Departamento de Historia del Arte de la Universidad de Castilla-La Mancha y dirigida por el catedrático D. Miguel Cortés Arrese. Algunos de los avances que en esta comunicación se presentan han sido expuestos en la I y III Jornada de Ciencia Joven y en el curso Arte y memoria en Castilla La Mancha con la ponencia Los castillos de la Orden de Calatrava, ambos organizados por el Departamento de Historia del Arte de la Facultad de Letras en la Universidad de Castilla La Mancha. 
Ciudad Real es una provincia del interior de la Península Ibérica que durante siglos ha sido una zona de paso, pues la necesidad de unir Córdoba, capital de la España islámica, con todos los rincones de la Península, proporciona la creación de nuevas vías de comunicación añadidas al sistema viario romano ${ }^{1}$, cuya importancia para Ciudad Real radica en que forzosamente tienen, en la mayor parte de los casos, que atravesar esta provincia en sentido vertical, de norte a sur, o diagonal, de suroeste a nordeste.

La Edad Media se adentra en el territorio hoy definido por la actual demarcación provincial de Ciudad Real, caracterizándose por ser esta una tierra de paso, prácticamente despoblada a causa de las empresas guerreras con los musulmanes. Dos fueron los aspectos condicionantes del esquema defensivo y la naturaleza de las fortificaciones manchegas, por un lado, las características físicas de la zona, como la falta de obstáculos internos naturales que pudieran servir de barrera natural o de apoyo a barreras artificiales, junto a los ríos fácilmente accesibles, y un segundo factor como la baja densidad de población, el establecimiento de una sociedad con intereses constructivos meramente dedicados a su propia defensa.

Solo cuando se alcance la estabilidad política centralizada, el arte comenzará a reflejarse en las edificaciones rurales. Será a partir del siglo XIII, cuando las zonas más llanas se poblarán protegiéndose con castillos, torres o murallas, como serán las construcciones que se hagan en relación con el número de sus habitantes, ejemplo de ello es el amurallamiento de Villa Real o Miguelturra, el castillo de Doña Berenguela en Bolaños de Calatrava, o la torre vigía de Fuente el Fresno, a medio camino entre el castillo de Guadalerzas en los Montes de Toledo y Calatrava la Vieja (fig. 1). El valor estratégico convertía a la actual provincia en escenario de operaciones militares, pero, por lo mismo, las consecuencias socioeconómicas no podían ser peores de cara a favorecer las manifestaciones artísticas ${ }^{2}$.

La aparición de las Órdenes Militares ${ }^{3}$ jugarán un papel esencial en el desarrollo artístico de Ciudad Real: Templarios, Sanjuanistas, Santiaguistas y Caballeros de la Orden de Calatrava se repartirán los territorios repercutiendo en el terreno artístico, impreciso en los lenguajes, pero que poco a poco, cada Orden, así como la Corona va imponiendo su personalidad. No obstante y desde la perspectiva historiográfica, la actual provincia de Ciudad Real ha permanecido en un segundo plano, bien por su localización, bien por la falta de recursos económicos necesarios para dar a conocer el rico patrimonio que posee en su extenso territorio.

La Edad Media ha dado lugar a diferentes debates en relación a su extensión temporal, su deuda con el pasado clásico y su consideración compleja. La lejanía en el

1 RUIBAL RODRÍGUEZ, Amador, Calatrava la Vieja. Estudio de una fortaleza medieval, Ciudad Real, Instituto de Estudios Manchegos, Consejo Superior de Investigaciones Científicas, 1984, p. 20.

2 LÓPEZ LÓPEZ, M M Cristina, "Ciudad Real artística tras las Navas de Tolosa", en SALVATIERRA CUENCA, Vicente y CRESSIER, Patrice (eds.), Las Navas de Tolosa 1212-2012 Miradas Cruzadas, Jaén, Universidad de Jaén, 2014, pp. 655-665.

3 IZQUIERDO BENITO, Ricardo, LÓPEZ-SALÁZAR PÉREZ, Jerónimo y RUIZ GÓMEZ, Francisco, Las Órdenes Militares en la Península Ibérica, Ciudad Real, Universidad de Castilla-La Mancha, 2000; PÉREZ MONZÓN, Olga, "El arte y las Órdenes Militares", en CAMPOS Y FERNÁNDEZ DE SEVILLA, Francisco Javier (coord.), Lux Hispaniarum: estudio sobre las Órdenes Militares, Real Consejo de las Órdenes, 1999, pp. 205-236. 


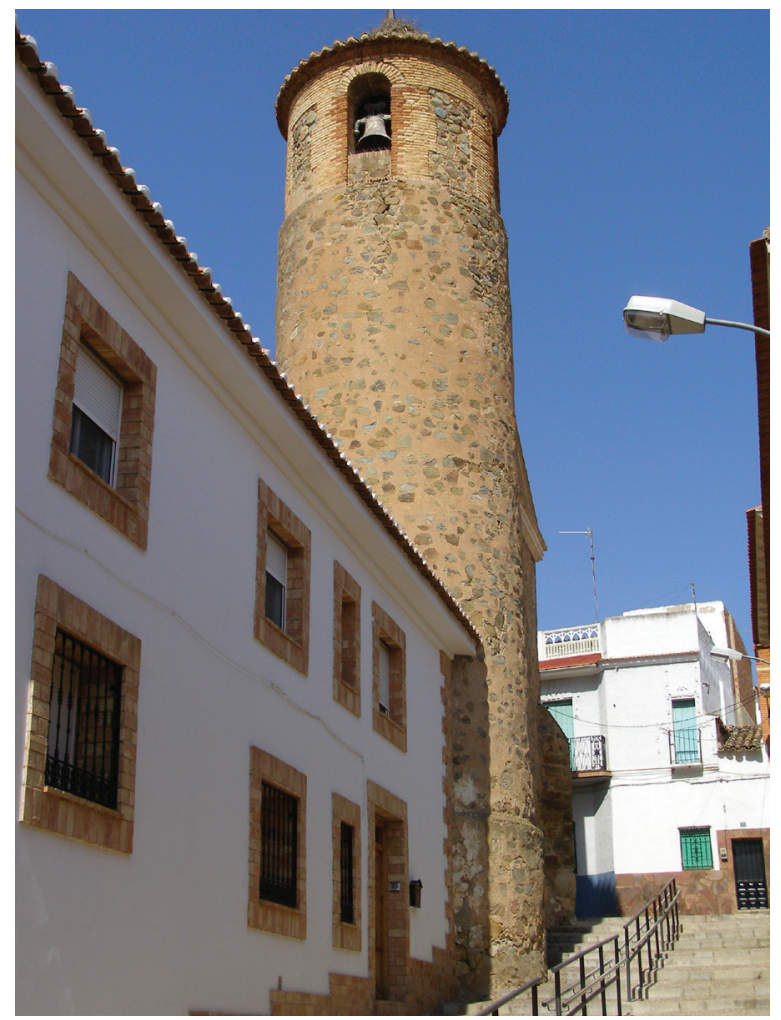

Fig. 1. Torre de la iglesia de Santa Quiteria. Fuente del Fresno.

tiempo, la falta de documentación con respecto a otros momentos posteriores y la pérdida o estado ruinoso de gran parte del patrimonio, hace necesaria la realización de estudios monográficos que sirvan para analizar este período en profundidad.

Los motivos que conducen al estudio del arte que se fomenta y crea durante los siglos XIV, XV y XVI en la provincia de Ciudad Real ${ }^{4}$, se centran en torno a una idea clave que puede centrarse en la inexistencia de un inventario preciso de bienes muebles e inmuebles en la provincia, el cual resulta necesario para el conocimiento del patrimonio, la cultura y la mentalidad de sus antiguos pobladores. Junto a esta idea clave se suma un nuevo factor, la escasa bibliografía dedicada al arte en la zona, siendo la existente, en su mayoría, trabajos de carácter parcial investigados por historiadores y autores locales interesados por el devenir histórico de sus poblaciones. La otra minoría ha ofrecido un replanteamiento de conjunto de las obras, destacando las más sobresalientes, y que a modo de síntesis no invalida los estudios parciales, sino

4 HERMOSO CUESTA, Miguel, "La investigación en Historia del Arte en España. Una reflexión personal", en Anales de Historia del Arte, no extraordinario 1, 2011, pp. 13-18. 
que, al contrario, sigue bebiendo de ellos pues son considerados imprescindibles para avanzar en la investigación.

Como objetivo principal del estudio se establece una catalogación actualizada de todas las edificaciones erigidas durante la Baja Edad Media, junto a la escultura y pintura que se fue desarrollando en el ámbito de la fábrica, debiendo ser numerosa, pues se concedía gran importancia al ornato de templos y ermitas, tanto por parte de los eclesiásticos, como de los nobles que, en ocasiones, contribuían sufragando algún retablo, imagen o pintura.

Encontramos en las fuentes citas y descripciones de muchas obras que no han llegado hasta nuestros días, debido en gran parte, al periodo desamortizador del siglo XIX, las Guerras Carlistas y, sobre todo, a la Guerra Civil Española de 1936-1939. Avatares que contribuyeron a la destrucción de gran parte del patrimonio artístico, consiguiendo en este primer objetivo de la investigación, la catalogación de las obras existentes y desaparecidas, convirtiéndose este en un estudio inédito. Es importante señalar que hasta la fecha no existe una catalogación actualizada de obras arquitectónicas, escultóricas y pictóricas, existentes o no, que pueda ofrecer una visión de conjunto sobre el arte que se manifiesta en el territorio que ocupa este estudio. Era ineludible la producción de un trabajo de investigación que ofreciera una catalogación de conjunto, tanto de los bienes que se han conservado in situ, como los que han cambiado su ubicación, o, simplemente, han desaparecido.

Un segundo objetivo es el análisis de la evolución tipológica en las artes ${ }^{5}$, teniendo en cuenta el extenso territorio del que nos ocupamos, las influencias artísticas percibidas en cada una de las fábricas; en escultura y pintura, a pesar de los contados ejemplos existentes, se analizan y comparan las obras, teniendo muy presente esta relación en primer lugar con la pertenencia al arzobispado de Toledo y, por ende, con la evolución del pensamiento de la época, comprobando los dominios de los acontecimientos sociopolíticos en la arquitectura, la escultura y la pintura.

El tercer objetivo planteado es el estudio de las manifestaciones artísticas escultóricas y pictóricas para comprender mejor los programas iconográficos y fijar las correspondientes atribuciones, profundizando de esta manera en aspectos relacionados con los maestros de obras, artesanos, canteros, etc., utilizando fuentes como contratos, comitentes, viajes o autoría de las obras.

Es importante señalar la relación de los diferentes estilos artísticos que se impregnan en las diferentes construcciones teniendo muy en cuenta los factores sociales, culturales y económicos que ofrecen las denominadas "tres culturas" 6 , cristiana, judía y musulmana. La recepción de los nuevos valores culturales de la época, el cambio de religiosidad y las influencias estéticas de los diferentes pueblos que conviven en el mismo territorio, van a generarse de forma paulatina y heterogénea.

5 ARÍZAGA BOLUMBURO, Beatriz, "La recuperación del paisaje urbano medieval: propuesta metodológica”, en BONACHÍA HERNANDO, Juan Antonio (coord.), La ciudad medieval: aspectos de la vida urbana en la Castilla bajomedieval, Valladolid, Universidad de Valladolid, Secretariado de Publicaciones e Intercambio Científico, 1996, pp. 13-33.

6 CORTÉS ARRESE, Miguel, "Tres culturas, un solo poder", en La Aventura de la Historia, n 4, 2007 (ejemplar dedicado a Así se hizo España: Castilla La Mancha), pp. 20-25. 
La metodología que se ha llevado a cabo, consta en primer lugar, de la lectura y estudio de las obras que aborden las artes en los siglos bajomedievales, primero en obras de carácter general, para centrarnos después en la Península Ibérica y en la región castellano-manchega, y finalizar con las obras dedicadas al estudio del arte en la provincia de Ciudad Real. Esta primera parte, que la tomamos como base, presente en el resto de la investigación, nos ha servido para realizar el capítulo dedicado al estado de la cuestión. En este capítulo se abordan, tanto las obras de carácter general que han dedicado algunas palabras a la provincia, catálogos artísticos o monumentales, diccionarios histórico-artísticos, como también obras de autores locales. Un punto de partida importante han sido las Relaciones Topográficas mandadas hacer por Felipe $\mathrm{II}^{7}$, ya que sin ellas no hubiésemos tenido en cuenta gran parte del patrimonio desaparecido. Ejemplo de ello es el caso de Montiel, en cuyo cuestionario se responde sobre la fortaleza de dicha villa poniendo de manifiesto la advocación de la iglesia del castillo y la imagen de alabastro del apóstol Santiago que en ella se guardaba treinta años después de su abandono:

"Y solía para la entrada de la dicha fortaleza haber en él barbacana, que es en una cerca, la puerta de palo, en la cual había una torre y adelante para entrar en lo principal de la fortaleza había a la puerta de hierro, y más adelante otra puerta que se llamaba la puerta del patio, que todas estas puertas habían de pasar para entrar en la dicha fortaleza, y antes de la barbacana había una cerca de piedra de mampuesto que venía a media cuesta y se guiaba desde el pie de la torre el Homenaje a dar a la iglesia vieja que le nombraban Nuestra Señora de la Estrella, y va a dar a la derecha de la ribera de Jabalón a ojo del camino que viene de Villahermosa a esta villa. Hay en la falda de este cerro donde está fundada la dicha fortaleza muchas peñas gruesas y señales de edificios de casas que no se tiene memoria del fundamento ni fin de ello; hay dentro de la dicha fortaleza una iglesia de bóveda muy principal donde está una imagen de alabastro de señor Santiago del Espada" .

El resultado que se espera obtener es el estudio del arte de transición entre la Edad Media y la Edad Moderna en la actual provincia de Ciudad Real, profundizando en cada una de las poblaciones, para poder llevar a cabo un análisis de la evolución de las artes, las posibles influencias que reciben de la mano de artistas formados en escuelas nacionales o extranjeras y cómo llegan a establecerse en la zona.

Tras el conocimiento y estudio de las obras bibliográficas de interés para la investigación se lleva a cabo la realización de una puesta en escena de los antecedentes artísticos que se manifiestan en el territorio. Castillos y ciudades-fortaleza erigidos sobre antiguos núcleos de asentamiento, datados desde la Edad del Bronce, así como asentamientos iberos y romanos, serán la base para conformar la red de fortificaciones que tienen todo su esplendor en época omeya, taifa y la definitiva repoblación bajo el dominio cristiano, tras la batalla de las Navas de Tolosa en 1212 .

7 CAMPOS Y FERNÁNDEZ DE SEVILLA, Francisco Javier (dir.), Los pueblos de Ciudad Real en "Las Relaciones Topográficas de Felipe II", Madrid, Ediciones Escurialenses, 2004.

8 CAMPOS Y FERNÁNDEZ DE SEVILLA, Francisco Javier (2004), op. cit., pp. 423-424. 


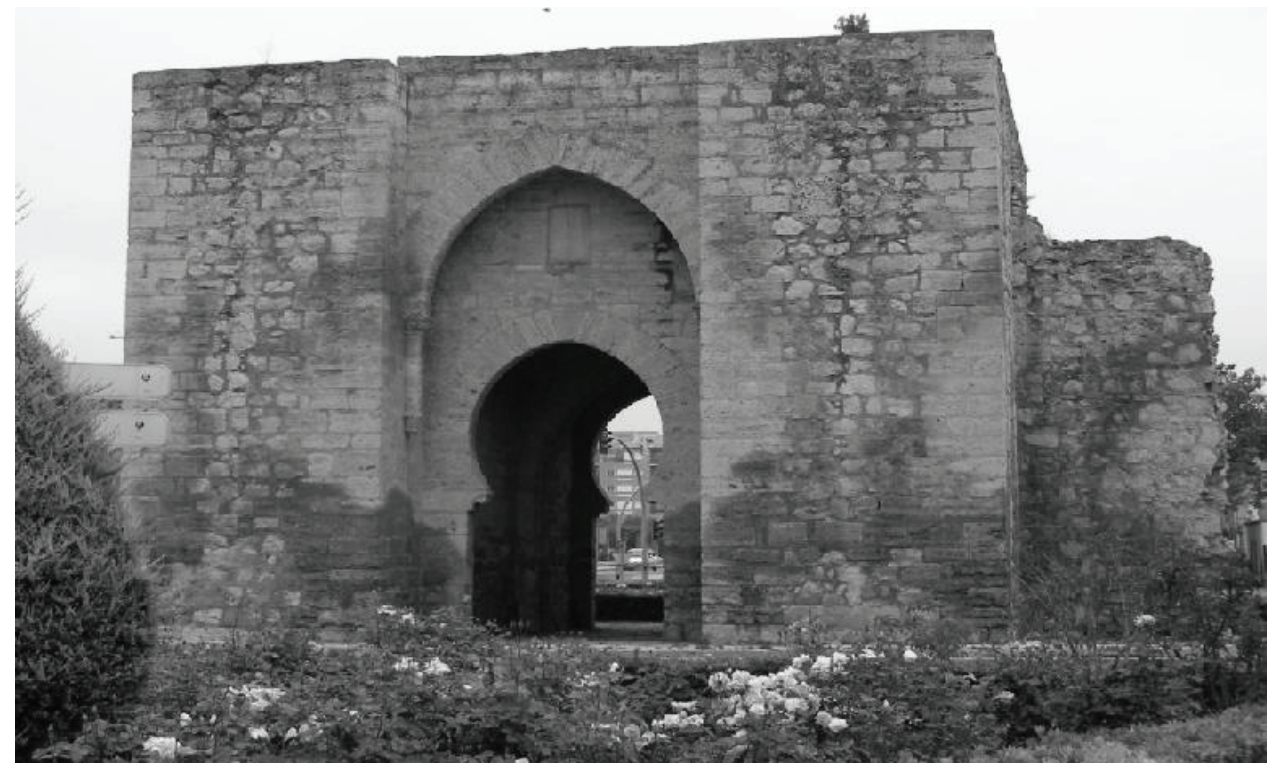

Fig. 2. Puerta de Toledo, Ciudad Real.

Las fortalezas responden a todo tipo de previsiones bélicas porque la defensa en la zona es una necesidad, convirtiéndose la arquitectura militar en la protagonista del panorama artístico regional, en el que coexistirán manifestaciones árabes, cristianas, mudéjares asentados en territorios cristianos y judíos. En palabras de Edward Cooper: "Los castillos atestiguan los gustos artísticos, los itinerarios habituales, las preocupaciones, la psicología, las crisis y hasta las finanzas de sus constructores" 9

Durante la repoblación cristiana se lleva a cabo el asentamiento de la población en lugares más llanos que se protegen con la construcción de murallas, torres, atalayas y castillos. Este es el caso del traslado de la población de Alarcos a la aldea de Pozuelo Seco de Don Gil, donde Alfonso X funda Villa Real en 1255, más tarde Ciudad Real. La cual, rodeada por una muralla de adobe fue fortificada con ciento treinta torres y siete puertas de las que se conserva únicamente la Puerta de Toledo (fig. 2). De Villa Real se analizan los tres templos más importantes, pero también se consideran las similitudes manifiestas en los rosetones de la basílica catedral de Ciudad Real y la ermita de Alarcos de la misma población.

Pertenecientes a estos primeros siglos de asentamiento son varios ejemplos de obras arquitectónicas analizadas y repartidas por todo el territorio ciudarrealeño. En el territorio de la Orden de San Juan, se analiza el Torreón del Gran Prior de Alcázar de San Juan (fig. 3). En el campo de Santiago, en la población de Fuenllana, se estu-

9 COOPER. Edward, Castillos Señoriales en la Corona de Castilla, Salamanca, Junta de Castilla y León, Consejería de Cultura y Turismo, 1991, p. 14. 


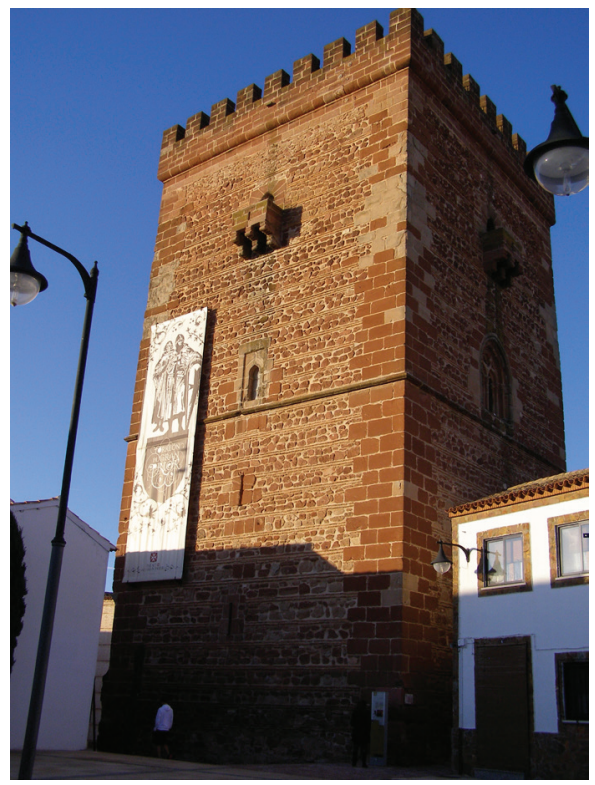

Fig. 3. Torreón del Gran Prior, Alcazar de San Juan.

dia la iglesia de Santa Catalina ${ }^{10}$, antigua capilla de la fortaleza (fig. 4). En el campo calatravo, la ermita de Alarcos, o en los Montes de Toledo, en Fontanarejo, la iglesia de San Felipe y Santiago.

Desde los siglos XII y XIII, en Europa, se aprecia un apogeo de culto a la Virgen María, tal y como lo demuestra la abundante iconografía mariana y advocaciones aún vigentes, capillas e iglesias dedicadas a la Virgen, nuevas oraciones y cánticos consagrados al culto mariano. Fruto de este esplendor, es la producción de la imaginería exenta de los siglos XIII y XIV, que presenta similitudes análogas en toda la Península Ibérica. Se trata de representaciones en madera policromada que representan la imagen de la Virgen, abandonando progresivamente los caracteres románicos que con la influencia franciscana trata de humanizar los rostros, buscando un sentido más realista ${ }^{11}$.

La imagen de la Virgen con Niño será un tema clásico en las representaciones artísticas del mundo cristiano, así pues podemos encontrar ejemplos de todo tipo, desde la clásica Virgen sentada con el Niño sobre su regazo, como pervivencia de la kiriotissa bizantina, hasta la Virgen con Niño de carácter afectuoso y naturalista como María madre del Niño Dios.

10 MOLINA CHAMIZO, Pilar, De la fortaleza al templo: arquitectura religiosa de la Orden de Santiago en la provincia de Ciudad Real: siglos XV-XVI, Ciudad Real, Diputación de Ciudad Real, 2006, vol.1, pp. 265-289.

11 CEBALlos ESCALERA, Isabel, Adquisiciones del Museo Arqueológico Nacional, 1940-45, Madrid, Museo Arqueológico Nacional, 1947, pp. 173-174. 


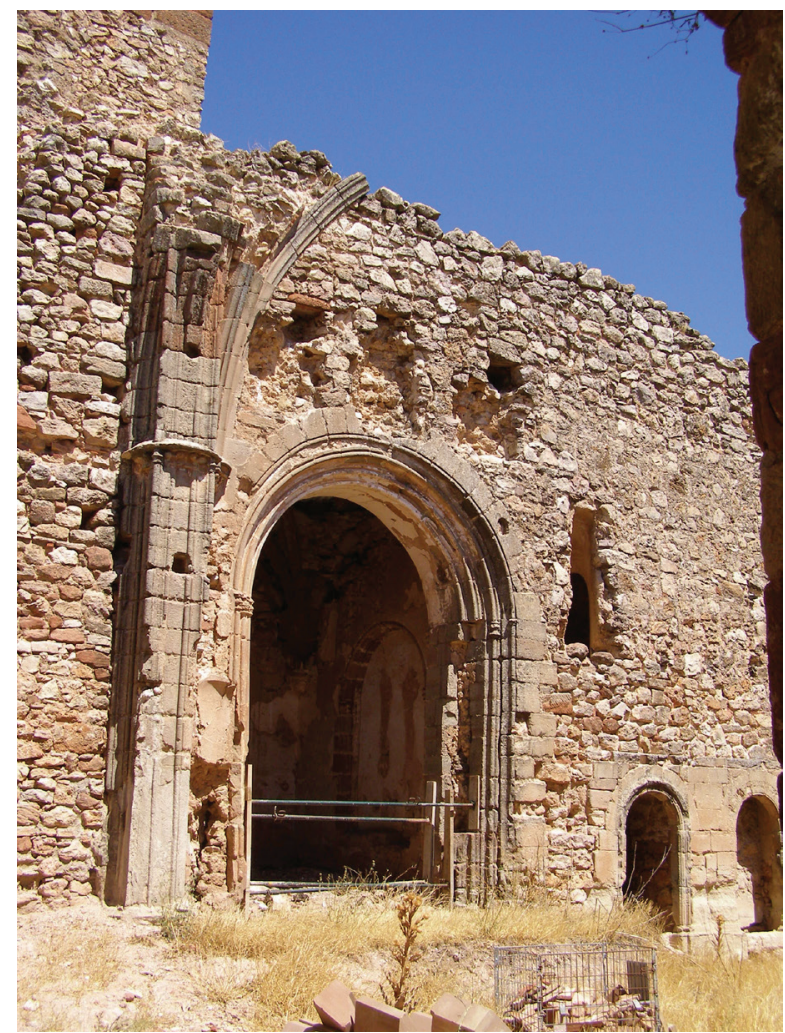

Fig. 4. Restos de la iglesia de Santa Catalina. Fuenllana.

Una decena son las imágenes esculpidas de la Virgen que encontramos repartidas por el amplio término de la provincia y que son analizadas en esta investigación. Ejemplo de ello es la Virgen de los Baños de Fuencaliente, o la conocida como "Porterita" recientemente trasladada del convento de Concepcionistas al Museo Diocesano de Ciudad Real (fig. 5), o la reciente localización de la imagen de Nuestra Señora de la Nava en Valenzuela de Calatrava.

La arquitectura erigida en el territorio que nos ocupa el presente estudio durante los siglos XIII, XIV, XV y los inicios del XVI, es una arquitectura en la que se mezclan las típicas técnicas constructivas procedentes de la cultura islámica, nuevos motivos decorativos y las novedades de estilo gótico tan asentadas en Francia y el Norte de España. La presencia de alarifes mudéjares y el bajo coste de los materiales empleados forjó una nueva estructura que se denominará gótico-mudéjar que se hizo patente en la mayoría de las nuevas construcciones y que coexistirán con las nuevas técnicas constructivas que se reciben procedentes de Italia. La pervivencia del modelo gótico-mudéjar va a convertirse en un freno a la adquisición de nuevas fórmulas renacentistas que se irán implantando en la zona de forma ralentizada. 


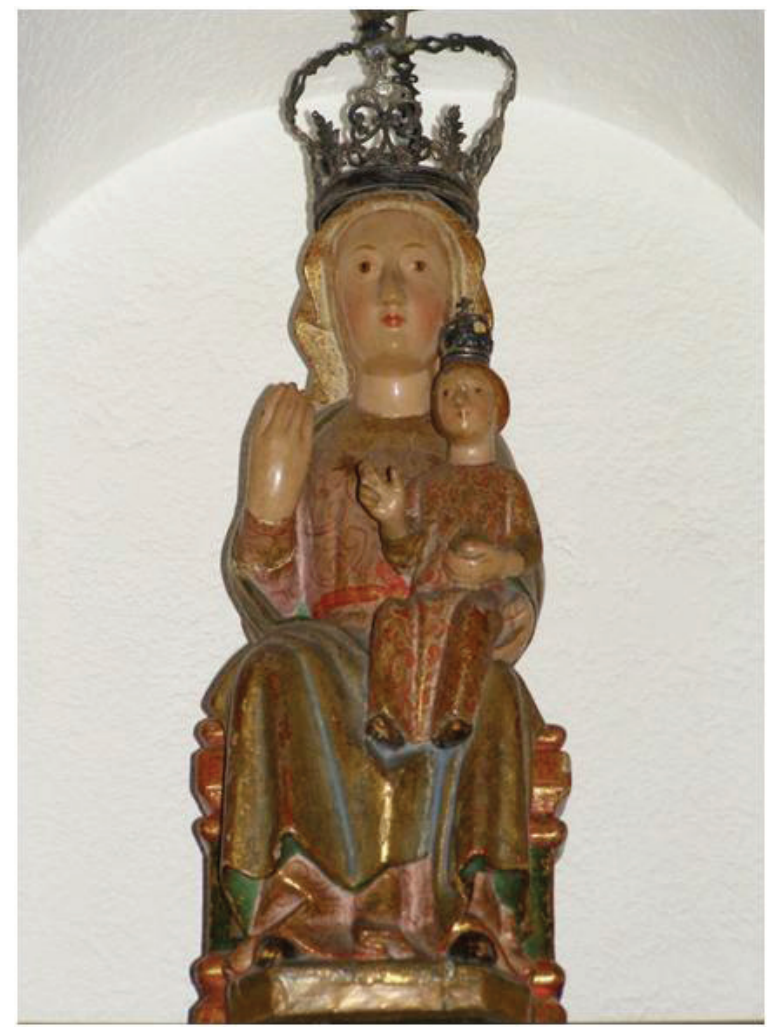

Fig. 5. La Porterita. Museo Diocesano de Ciudad Real.

La escultura que se ha conservado datada en los siglos que nos ocupa la investigación apenas se ha conservado, es escasa y ofrece en la mayor parte de los casos un claro reflejo de la transición de las formas góticas adquiriendo paulatinamente rasgos naturalistas y humanizados en referencia a una transición a las formas renacentistas.

La pintura que ha llegado hasta nosotros, de temática religiosa, y cuya técnica predomina el óleo sobre tabla o lienzo, se conserva en el Museo Diocesano de Ciudad Real, como el Entierro de Cristo y otros ejemplos más tardíos en los que se advierten influencias italianas, del Greco y Yáñez de la Almedina. En pintura mural, no podemos dejar pasar por alto los restos encontrados en la iglesia de Nuestra Señora de las Angustias de Arenas de San Juan, donde se representa la Santa Cena y las escenas halladas en el ábside de la iglesia parroquial de Arroba de los Montes donde se representa la toma de Toledo. Pero el máximo exponente de pintura renacentista en temática mitológica, se encuentra en el Palacio de Don Álvaro de Bazán en Viso del Marqués, al sur de la provincia (fig. 6). Pinturas realizadas por artistas ${ }^{12}$ traídos

12 LÓPEZ TORRIJOS, Rosa, "Sobre pintores italianos en España (Castello, Perolli y el falso Cesare Arbasia en el palacio del Viso", en In sapienta libertas: escritos en homenaje al profesor Alfonso E. Pérez 


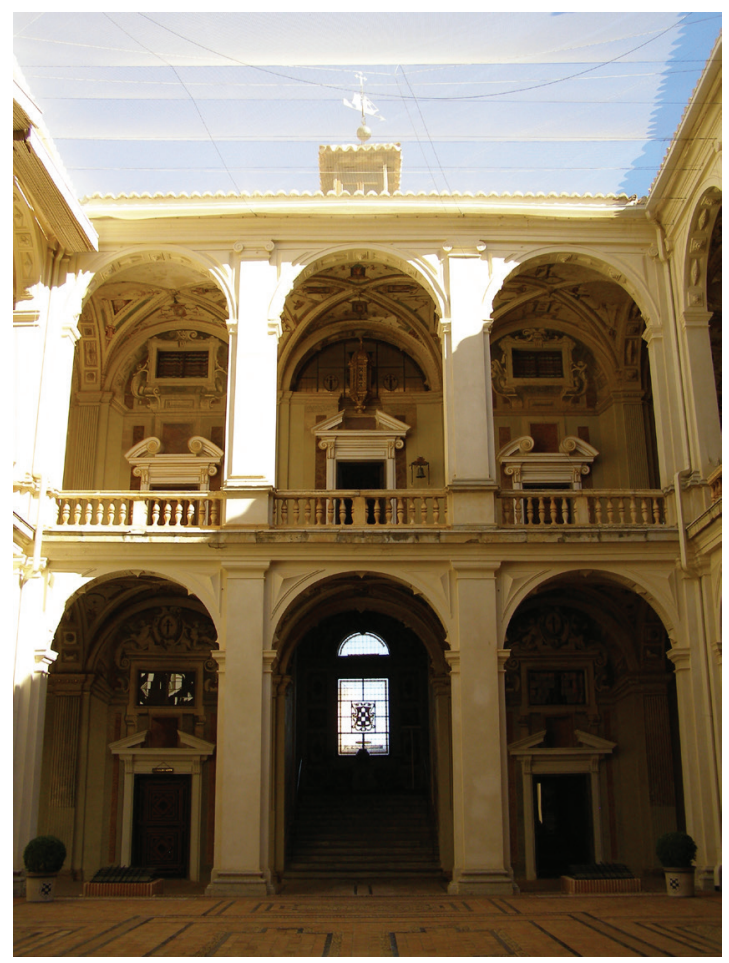

Fig. 6. Palacio del Marqués de Santa Cruz. Viso del Marqués.

de Génova ${ }^{13}$ en los inicios del siglo XVII, pintores que trabajarán posteriormente en algunas poblaciones de los alrededores y que tomaremos como colofón en este arte de transición del gótico al renacimiento en la provincia de Ciudad Real.

Sánchez, Madrid, Museo del Prado, 2007, pp. 198-202.

13 LÓPEZ TORRIJOS, Rosa, Entre España y Génova: el Palacio de Don Álvaro de Bazán en el Viso, Madrid, Ministerio de Defensa, 2009. 